\title{
Influence of nickel addition on magnetic and electro-mechanical behaviour of permalloys
}

\author{
KIRAN GUPTA ${ }^{\dagger}$, K K RAINA* and S K SINHA ${ }^{\dagger}$ \\ School of Physics and Materials Science, Thapar Institute of Engineering \& Technology, Patiala 147 004, India \\ ${ }^{\dagger}$ National Research and Technology Consortium, Sector-1, Parwanoo 173 220, India
}

MS received 8 February 2006; revised 16 May 2006

\begin{abstract}
Magnetic and electro-mechanical investigations have been carried out in two Ni-Fe permalloys under hydrogen atmosphere by varying annealing temperature. These alloys have been characterized for various magnetic parameters like peak permeability, coercivity and core loss under changed annealing profile conditions. The magnetic properties of Ni-rich $(\mathrm{Ni} \sim 82 \%)$ alloy at $100 \mathrm{~Hz}$ were found to be better than the low $\mathrm{Ni}$ (Ni $\sim 47 \%$ ) alloy. The alloys were tested for watch movement and found that the battery life of the watch movement improved by $38 \%$ using Ni-rich permalloy.
\end{abstract}

Keywords. Ni-rich alloy; low $\mathrm{Ni}$ alloy; annealing temperature; magnetic properties; electro-mechanical behaviour.

\section{Introduction}

The Ni-Fe soft magnetic alloys are the ductile and most versatile soft magnetic alloys currently in use in many industrial applications. Compared to silicon-iron electrical steels, they exhibit much higher permeabilities and lower core loss. A large number of elements can enter into solid solution, permitting tailoring of their magnetic and physical properties. Three ranges of nickel content are used as soft magnetic alloys: $36 \% \mathrm{Ni}$ for maximum resistivity, 50\% $\mathrm{Ni}$ for maximum saturation magnetization and $80 \% \mathrm{Ni}$ for optimum initial and maximum permeabilities (Akomolafe and Johnson 1989; ASM internationals 1995). Of the above alloys, $50 \% \mathrm{Ni}$ and $80 \% \mathrm{Ni}$ alloys are most widely used in rotor and stator laminations, stepping motors, shieldings, relay parts etc.

Watch is an electromechanical device, which contains some mechanical, electrical and magnetic components. The heart of the movement is a bipolar stepper motor that converts electrical energy to magnetic energy and then to mechanical motion. The stepper motor consists of a rotor, a stator and a coil. The rotor is formed by a permanent magnet whereas core and stator are made up of $\mathrm{Ni}-\mathrm{Fe}$ alloy. The coil is wound on the core such that core and stator are then mechanically joined to complete the magnetic circuit of the stepper motor. Electronic circuit board supplies the necessary d.c. voltage pulses to the coil in such a manner that the current flows in one direction when the first pulse is applied and vice versa after one second. This process keeps on repeating every second, thereby

\footnotetext{
*Author for correspondence (rainatietp@yahoo.com)
}

producing an alternate polarity magnetic field in the stator. Since the core and stator are made up of soft magnetic materials (such as $\mathrm{Ni}-\mathrm{Fe}$ alloy), when the current flows in the coil it becomes magnetized and temporary north and south poles are created and rotor is moved by $180^{\circ}$. When current is flown in reverse direction, the north pole becomes south and south changes to north. The rotor moves further $180^{\circ}$ and this process keeps on repeating.

In addition to the control on metallurgical process of the magnetic material, the magnetic properties of both the alloys depend on the heat treatment under hydrogen atmosphere (Bozorth 1951; Enoch and Fudge 1966; Scholefield et al 1967; Pfeifer and Radeloff 1980). The magnetic properties of these alloys also depend on the values of the anisotropy and magnetostriction constants. Both the parameters depend further on the degree of short range order (SRO) developed in the materials (Akomolafe and Johnson 1989). Optimum magnetic properties are obtained when a critical degree of SRO is developed in these alloys, which allow both the anisotropy energy and magnetostriction constant to be simultaneously reduced to small values. Various degrees of order can be obtained by controlled cooling of the specimens at different rates in the temperature range between about $500^{\circ} \mathrm{C}$ and $400^{\circ} \mathrm{C}$. Peak permeability, coercivity and hysteresis loss are highly structure sensitive properties (Bozorth 1951). These properties are frequency dependent (Walker Sci. Inc. 1997; Sankyo Standards 1998; Krupp 2000; Thyssenkrupp 2002) as can be understood from the equation

$$
P_{\mathrm{c}}=\frac{N_{1} f}{N_{2}} \int_{0}^{T} I_{1}(t) V_{2}(t) \mathrm{d} t,
$$


where $P_{\mathrm{c}}$ is specimen core loss (watts), $N_{1}$ the number of primary turns, $N_{2}$ the number of secondary turns, $f$ the test frequency $(\mathrm{Hz})$ and $T$ the period of one cycle.

$$
\text { Permeability, } \mu=\frac{E}{h f}\left[3.978 \times 10^{5}\right] \text {, }
$$

where $E$ is the emf generated $(\mathrm{mV}), h$ the thickness of the sample $(\mathrm{cm})$ and $f$ the frequency.

Improvement in magnetic properties of the alloys (such as low coercivity and high permeability) plays a key role for improving electro-mechanical properties by reducing the current consumption and thereby increasing the battery life of watch.

In this paper, two novel samples of Ni-Fe alloys were prepared. These were annealed in dry hydrogen by varying the annealing temperature from $1100-1180^{\circ} \mathrm{C}$ under controlled cooling. The structure sensitive a.c. magnetic properties (such as coercivity, permeability and core loss) were studied at different frequencies. The electromechanical properties such as torque and battery life of the movement were also reported.

\section{Experimental}

The alloys used in the study were of commercial grade, one rich in nickel content (about $82 \% \mathrm{Ni}$ ) and the other low in nickel content (about $47 \% \mathrm{Ni}$ ). Required thicknesses of the materials were obtained by cold rolling the materials without interstage annealing. The structure of both the alloys was face-centred cubic $(f c c)$ austenite (Dietrich 1990). The elements and composition of the alloys were determined by wet chemical analysis and atomic absorption spectrophotometer as given in table 1 .

The magnetic properties of both the alloys were very much dependent on processing and heat treatment. The parts made from these alloys were annealed in pure dry hydrogen for several hours to eliminate stresses, and to increase grain size. They were cooled down to the critical ordering temperature range. The rate of cooling through the ordering range was typically $55-350^{\circ} \mathrm{C} / \mathrm{h}$ depending on the alloy being heat treated. The nickel rich alloy has high permeability and low core loss but also has a saturation

Table 1. Composition of the Ni-Fe alloys used in present study.

\begin{tabular}{lcc}
\hline Element & High Ni alloy & Low Ni alloy \\
\hline $\mathrm{Ni}$ & $82 \cdot 13$ & $47 \cdot 01$ \\
$\mathrm{Fe}$ & $12 \cdot 38$ & 49.50 \\
$\mathrm{Mo}$ & $5 \cdot 00$ & - \\
$\mathrm{Mn}$ & $0 \cdot 43$ & 0.38 \\
$\mathrm{C}$ & $0 \cdot 02$ & 0.05 \\
$\mathrm{Si}$ & Traces & 0.63 \\
$\mathrm{Co}$ & - & 0.03 \\
\hline
\end{tabular}

induction of only about $0.8 \mathrm{~T}$ (Gupta et al 2005a). Alloying additions of 4-5\% Mo to this alloy, served to accentuate its particular magnetic characteristics. The low nickel alloy was lower in permeability than that of Ni-rich alloy. But the low nickel alloy had a higher saturation induction of about 1.6 T (Li 2001; Gupta et al 2005b,c). To achieve the desired magnetic properties such as high permeability, low core loss and low coercivity, the materials were annealed in $\mathrm{H}_{2}$ atmosphere in the temperature range $1100-1180^{\circ} \mathrm{C}$. The details of the annealing profiles performed on the samples are given in table 2 . The samples were prepared in the form of rings, core and stator punched from the sheet material.

The magnetic measurements were carried out on the toroid shape samples by stacking rings having outer diameter, $10 \mathrm{~mm}$ and inner diameter, $6 \mathrm{~mm}$ and using 20 numbers of primary and secondary turns. AC magnetic measurements under different processing parameters were carried out using B-H analyser (AMH-401, Walker Scientific, USA). The magnetic properties such as coercivity, peak permeability and core loss have been evaluated at different frequencies by varying the field strength. The annealed samples in the form of coil core and stator were tested in the watch movement. The current consumption of the movement was measured at $1.5 \mathrm{~V}$ by increasing the resistance of the coil core up to $3.50 \mathrm{~K} \Omega$ and simultaneously the torque of the movement was measured using torque meter (Witchi). The standard battery, SR 626, having battery life of $24 \mathrm{mAh}$ was used in the movement. The standard formula used for calculating the battery life is

Battery life of movement $(h)=$

Standard life of battery

Current consumption of the movement

\section{Results}

\subsection{Magnetic properties of high Ni alloy}

The magnetic properties (such as coercivity $\left(H_{\mathrm{c}}\right)$, peak permeability $(\mu)$ and core loss $\left.\left(P_{\mathrm{c}}\right)\right)$ of Ni-rich alloy as a function of annealing temperature at different frequencies are given in figure 1 .

Figure 1a shows that at $1100^{\circ} \mathrm{C}$ temperature, the coercivity increases from $24.45 \mathrm{~A} / \mathrm{m}-42 \cdot 19 \mathrm{~A} / \mathrm{m}$ with increase in frequency from $100-150 \mathrm{~Hz}$ and reaches $78.51 \mathrm{~A} / \mathrm{m}$

Table 2. Annealing profiles of the Ni-Fe alloys.

\begin{tabular}{lcc}
\hline $\begin{array}{l}\text { Annealing } \\
\text { temperature } \\
\left({ }^{\circ} \mathrm{C}\right)\end{array}$ & $\begin{array}{c}\text { Holding time } \\
(\mathrm{h})\end{array}$ & $\begin{array}{c}\text { Cooling rate through } \\
\text { the ordering range } \\
\left(700-300^{\circ} \mathrm{C} / \mathrm{min}\right)\end{array}$ \\
\hline $1100,1120,1140$, & 2 & $2 \cdot 5$ \\
$1150,1160,1180$ & & \\
\hline
\end{tabular}


with further increase in the frequency to $300 \mathrm{~Hz}$. Similar effect has been observed at other higher annealing temperatures. Figure $1 \mathrm{~b}$ shows that the peak permeability at $1100^{\circ} \mathrm{C}$ temperature decreases from 10996-5769 with increase in frequency from $100-150 \mathrm{~Hz}$. However, the peak permeability decreases to 3000 with further increase
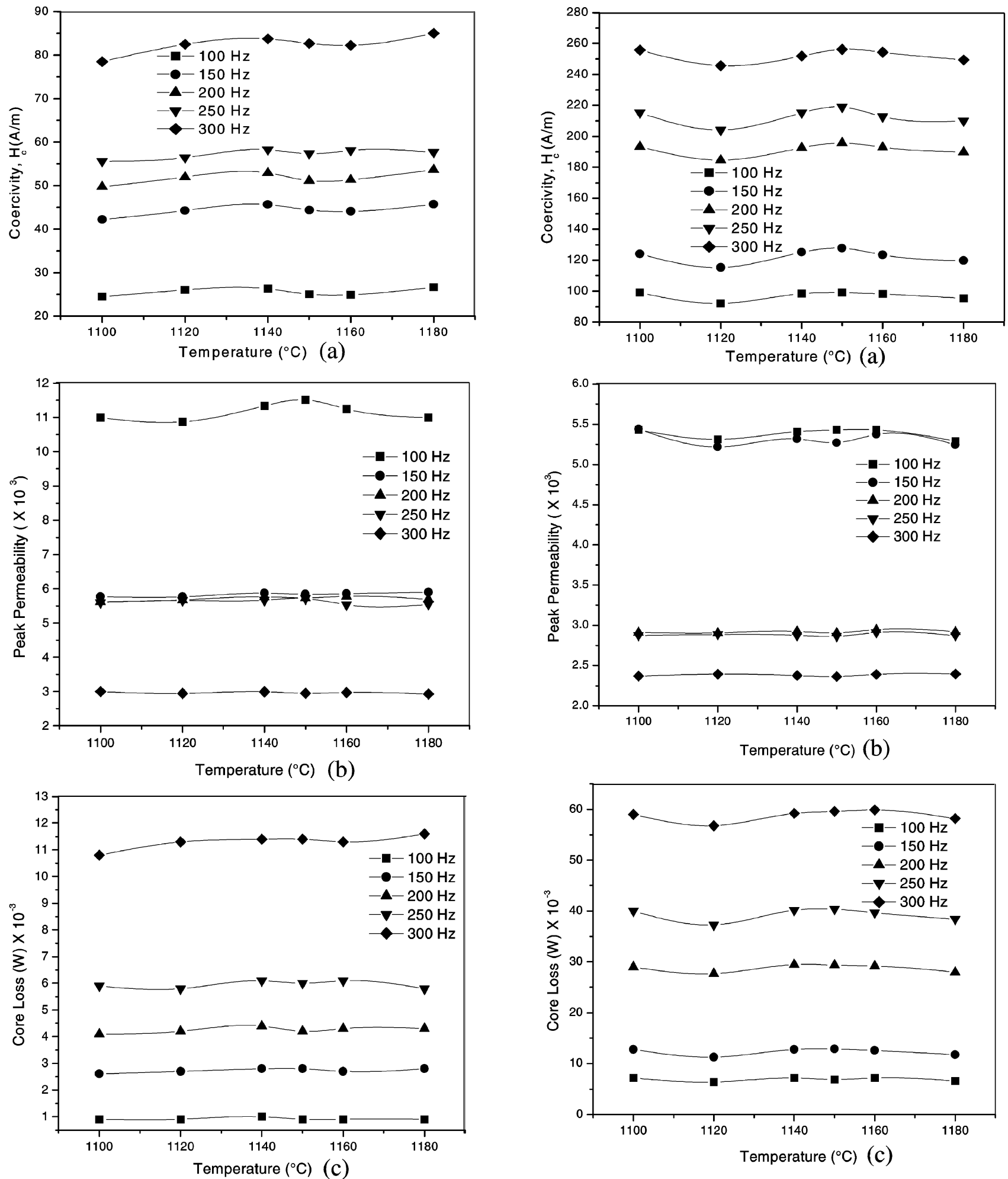

Figure 1. Effect of annealing temperature on (a) coercivity, (b) peak permeability and (c) core loss of Ni-rich alloy at different frequencies.

Figure 2. Effect of annealing temperature on (a) coercivity, (b) peak permeability and (c) core loss of low Ni alloy at different frequencies. 
Table 3. Effect of annealing temperature on coercivity.

\begin{tabular}{lccccc}
\hline & \multicolumn{2}{c}{ Coercivity $(\mathrm{A} / \mathrm{m})$ at $100 \mathrm{~Hz}$} & & \multicolumn{2}{c}{ Coercivity $(\mathrm{A} / \mathrm{m})$ at $300 \mathrm{~Hz}$} \\
\cline { 2 - 3 } \cline { 5 - 5 } Annealing temperature $\left({ }^{\circ} \mathrm{C}\right)$ & High Ni alloy & Low Ni alloy & & High Ni alloy & Low Ni alloy \\
\hline 1100 & $24 \cdot 45$ & $99 \cdot 01$ & & $78 \cdot 51$ & $255 \cdot 78$ \\
1120 & $26 \cdot 04$ & $92 \cdot 07$ & & $82 \cdot 47$ & $245 \cdot 69$ \\
1140 & $26 \cdot 29$ & $98 \cdot 49$ & & $83 \cdot 74$ & 251.96 \\
1150 & $25 \cdot 05$ & $99 \cdot 14$ & & $82 \cdot 70$ & $256 \cdot 25$ \\
1160 & $24 \cdot 92$ & $98 \cdot 25$ & & $82 \cdot 23$ & $254 \cdot 41$ \\
1180 & $26 \cdot 65$ & $95 \cdot 36$ & & $85 \cdot 01$ & $249 \cdot 38$ \\
\hline
\end{tabular}

Table 4. Effect of annealing temperature on peak permeability.

\begin{tabular}{lccccc}
\hline & \multicolumn{2}{c}{ Peak permeability at $100 \mathrm{~Hz}$} & & \multicolumn{2}{c}{ Peak permeability at $300 \mathrm{~Hz}$} \\
\cline { 2 - 3 } \cline { 5 - 5 } Annealing temperature $\left({ }^{\circ} \mathrm{C}\right)$ & High Ni alloy & Low Ni alloy & & High Ni alloy & Low Ni alloy \\
\hline 1100 & 10996 & 5429 & & 3000 & 2370 \\
1120 & 10870 & 5312 & & 2947 & 2394 \\
1140 & 11337 & 5407 & & 2996 & 2376 \\
1150 & 11512 & 5430 & & 2950 & 2364 \\
1160 & 11246 & 5429 & & 2972 & 2390 \\
1180 & 10995 & 5291 & & 2930 & 2395 \\
\hline
\end{tabular}

Table 5. Effect of annealing temperature on core loss.

\begin{tabular}{lccccc}
\hline & \multicolumn{2}{c}{ Core loss $(\mathrm{mW})$ at $100 \mathrm{~Hz}$} & & \multicolumn{2}{c}{ Core loss $(\mathrm{mW})$ at $300 \mathrm{~Hz}$} \\
\cline { 2 - 3 } \cline { 5 - 5 } Annealing temperature $\left({ }^{\circ} \mathrm{C}\right)$ & High Ni alloy & Low Ni alloy & & High Ni alloy & Low Ni alloy \\
\hline 1100 & $0 \cdot 9$ & $7 \cdot 2$ & & $11 \cdot 0$ & $59 \cdot 0$ \\
1120 & 0.9 & $6 \cdot 4$ & & $11 \cdot 0$ & $56 \cdot 0$ \\
1140 & $1 \cdot 0$ & $7 \cdot 2$ & & $11 \cdot 0$ & $59 \cdot 0$ \\
1150 & $0 \cdot 9$ & $6 \cdot 9$ & & $11 \cdot 0$ & $59 \cdot 0$ \\
1160 & $0 \cdot 9$ & $7 \cdot 2$ & & $11 \cdot 0$ & $59 \cdot 0$ \\
1180 & 0.9 & $6 \cdot 6$ & & $11 \cdot 0$ & $58 \cdot 0$ \\
\hline
\end{tabular}

in the frequency to $300 \mathrm{~Hz}$. Similar behaviour has been observed at other annealing temperatures. Similarly, at $1100^{\circ} \mathrm{C}$ temperature, the core loss increases from 0.9 $2.6 \mathrm{~mW}$ with increase in frequency from $100-150 \mathrm{~Hz}$ (figure $2 \mathrm{c}$ ) and reaches to $10 \cdot 8 \mathrm{~mW}$ with further increase in the frequency to $300 \mathrm{~Hz}$. Similar effect has been observed at other annealing temperatures.

\subsection{Magnetic properties of low Ni alloy}

Similarly, the magnetic properties (such as coercivity, $H_{\mathrm{c}}$, peak permeability and core loss) of low $\mathrm{Ni}$ alloy as a function of annealing temperature at different frequencies are given in figure 2 .

Figure $2 \mathrm{a}$ shows that at $1100^{\circ} \mathrm{C}$, the coercivity increases from $99.01 \mathrm{~A} / \mathrm{m}-124.11 \mathrm{~A} / \mathrm{m}$ with increase in frequency from $100-150 \mathrm{~Hz}$ and reaches to $255.78 \mathrm{~A} / \mathrm{m}$ with further increase in the frequency up to $300 \mathrm{~Hz}$. Similar effect has been observed at other annealing temperatures. Figure $2 \mathrm{~b}$ shows that the peak permeability at $1100^{\circ} \mathrm{C}$ temperature decreases slightly from 5439-5429 with increase in frequency from $100-150 \mathrm{~Hz}$ but decreased to 2370 with further increase in the frequency to $300 \mathrm{~Hz}$. Similar behaviour has been observed at other annealing temperatures. Similarly, the core loss at $1100^{\circ} \mathrm{C}$ temperature increases from $7 \cdot 2-12 \cdot 8 \mathrm{~mW}$ with increase in frequency from $100-150 \mathrm{~Hz}$ (figure $2 \mathrm{c}$ ) and reaches to $5.9 \mathrm{~mW}$ with further increase in the frequency to $300 \mathrm{~Hz}$. Similar effect has been observed at other annealing temperatures.

\subsection{Comparison of magnetic properties of high $\mathrm{Ni}$ and low Ni alloy}

The comparison of magnetic properties of both the alloys are given in tables $3-5$. It has been noticed that at $1100^{\circ} \mathrm{C}$ and at $100 \mathrm{~Hz}$, the coercivity of Ni-rich alloy is less $(24.45 \mathrm{~A} / \mathrm{m})$ in comparison to low $\mathrm{Ni}$ alloy $(99.01 \mathrm{~A} / \mathrm{m})$ as given in table 3 , the peak permeability of Ni-rich alloy is high (10996) in comparison to low Ni alloy (5429) as given in table 4 and core loss of Ni-rich alloy is less 


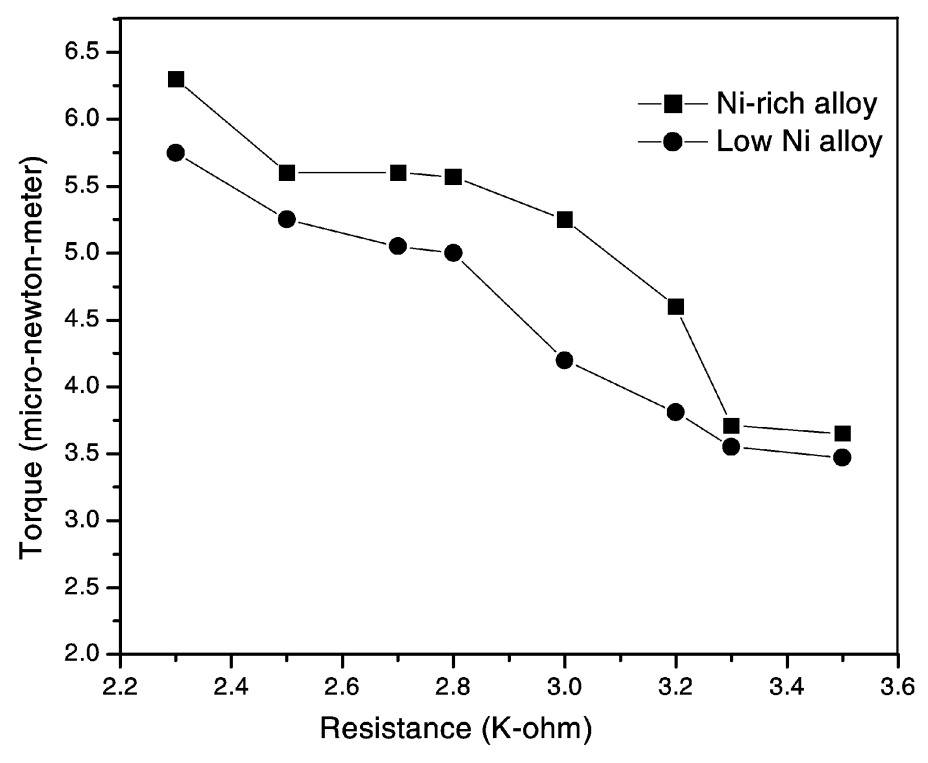

Figure 3. Torque of watch movement as a function of resistance.

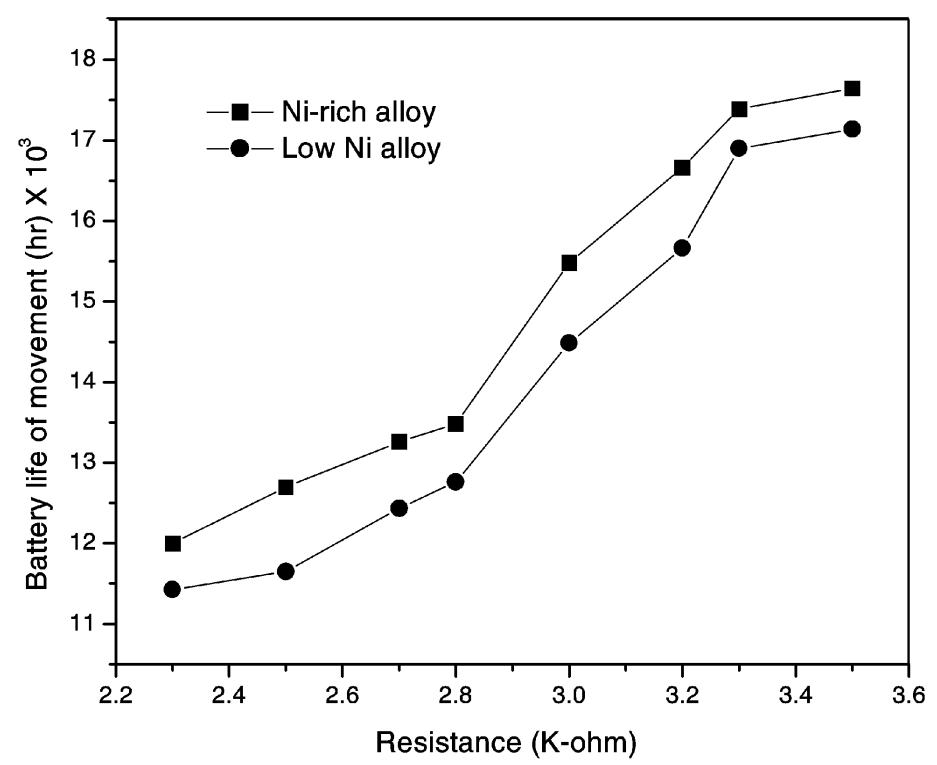

Figure 4. Battery life of watch movement as a function of resistance at $1.5 \mathrm{~V}$ bias.

$(0.9 \mathrm{~mW})$ in comparison to low $\mathrm{Ni}$ alloy $(7.2 \mathrm{~mW})$ as given in table 5. Similar behaviour of coercivity, peak permeability and core loss were noticed for other higher temperatures and higher frequencies (tables 3-5).

The higher permeability of $\mathrm{Ni}$ rich alloy is due to the production of a significant degree of SRO during slow cooling through the ordering temperature range. The presence of Mo element in Ni-rich alloy slows down the ordering kinetics and lowers the degree of long range order thereby increase the resistivity and simplifies the final heat treatment and hence improves the properties such as permeability and other magnetic properties.

\subsection{Electro-mechanical behaviour}

The torques of the high $\mathrm{Ni}$ and low $\mathrm{Ni}$ alloys are given in figure 3 . The acceptable limit of torque is $4.55 \mu \mathrm{Nm}$. It has been observed that in high $\mathrm{Ni}$ alloy, resistance of the coil core can be increased from $2.30 \mathrm{~K} \Omega$ (existing) to $3.20 \mathrm{~K} \Omega$ by maintaining the acceptable limit of torque but in low $\mathrm{Ni}$ alloy the resistance of coil core can be increased only up to $2.80 \mathrm{~K} \Omega$ (figure 3 ). The battery life of the movement with Ni-rich alloy has been improved by $38 \%$ with the existing low $\mathrm{Ni}$ alloy as given in figure 4 . 


\section{Conclusions}

From the above study, we conclude that the magnetic properties of the high $\mathrm{Ni}(\mathrm{Ni} \sim 82 \%)$ alloy are better in comparison to low $\mathrm{Ni}(\mathrm{Ni} \sim 47 \%)$ alloy at lower frequency i.e. $100 \mathrm{~Hz}$. The alloys were tested for watch operation and found that the battery life of the watch movement improved by $38 \%$ using Ni-rich permalloy.

\section{Acknowledgements}

The authors wish to express their sincere gratitude to the referees for valuable suggestions and comments. They are thankful to the Department of Science and Technology, Government of India, for providing financial support for the work through the research project III.5 (99)/97-E.T. Authors are also thankful to $\mathrm{M} / \mathrm{s}$ Purewal \& Associates, Jubbar (HP), for help in the measurement of electromechanical properties of watch movement.

\section{References}

Akomolafe T and Johnson G W 1989 J. Appl. Phys. 24349
ASM Handbook of Metallography and Microstructures 1995 (Materials Park, Ohio: ASM International) 9 p. 538

Bozorth R M 1951 Ferromagnetism (New York: D. Van Nostrand Company Inc) 14

Dietrich D W 1990 Magnetically soft materials, properties and selection: Nonferrous alloys and special purpose materials ASM Handbook (Materials Park, Ohio: ASM International) 2 p. 761

Enoch R D and Fudge A D 1966 Br. J. Appl. Phys. 17623

Gupta Kiran, Sinha S K and Raina K K 2005a Proc. nat. conf. on advances in condensed matter physics (Patiala: TIET) p. 11

Gupta Kiran, Sinha S K and Raina K K 2005b Proc. nat. conf. on materials for electrical, electronic and magnetic applications: Characterization and measurements (Hyderabad: DMRL) p. $6 \mathrm{~B} .5$

Gupta Kiran, Raina K K and Sinha S K 2005c Ind. J. Eng. \& Mater. Sci. 12577

Krupp V D M 2000 Magnifer 7904, Data Sheet No. 9004

Li Lin 2001 IEEE Trans. Mag. 372315

Pfeifer F and Radeloff C 1980 J. Magn. \& Magn. Mater. 19190

Sankyo Standards, Japan 1998 Special Quality Manual 4

Scholefield H H, Major R V, Gibson B and Martin A P 1967 Br. J. Appl. Phys. 1841

Thyssenkrupp V D M 2002 Magnifer 50, Data Sheet No. 9002

Walker Scientific Inc, USA 1997 Instruction Manual, automatic hysteresis graph, AMH-401 